\title{
Safety Pesticides Indicator using Hardware Model
}

\author{
Karkuzhali S, Siri Chandana S
}

\begin{abstract}
Pesticides are extensively used in agricultural production to prevent or control pest, diseases, weeds and plant pathogens in an effect to diminish or eradicate yield losses and maintain high product eminence. In this pesticide process the farmers are widely affected by using pesticides, the potential solution for this problem is a safety pesticide indicator and this indicator helps the farmer to use pesticides in harmless manner. The proposed method is used to develop the hardware and software application for the Safety Pesticide Indicator. This pesticides indicator will ensure the safety of farmer and prevent the soil pollution from harmful pesticides
\end{abstract}

Keywords : Agriculture, pesticides, indicator, disease prevention, hardware

\section{INTRODUCTION}

$\mathrm{T}$ he over usage of pesticide causes damage to plants, farmers and create soil pollution. Agriculture field react differently when pouring maximum amount of pesticide. If pesticide tanker becomes empty the farmers have not noticed that for using the indicator in agriculture field. So we connect indicator in the pesticide indicator. With the help of indicator farmer can able to predict level of pesticide. If it exiting the limit the sensor gives the alert to the farmer. If this idea is implemented we can check the indicator in the pesticide tanker can spontaneously fine it. It will be help to farmers and up coming agriculture farmers. Figure 1 illustrate the need for safety pesticides indicator.

\section{EXISITING METHOD}

Muhammad et al. gives some steady data to raised see customary collect protection issues and related practices of farmers in cotton age inside the space. Farmers had a few information concerning the impact of disturbances on cotton yield inside the space, at any rate there have been key openings related with right tormenter conspicuous evidence, right usage of pesticides, and issues of prosperity [2].

Ranchers required training inside the distinguishing proof of irritations, regular adversaries, fundamental environment and coordinated tormenter the board techniques to ensure

Revised Manuscript Received on December 16, 2019.

* Correspondence Author

Karkuzhali S, Associate Professor, Department of Computer Science and Engineering, School of Computing, Kalasalingam Academy of Research and Education, Tamilnadu, India.

Siri Chandana S, IV Year B.Tech Computer Science and Engineering, Kalasalingam Academy of Research and Education, Tamilnadu, India. property creation of cotton. the supposition among ranchers that bug sprays by and by utilized aren't in this manner powerful or not successful even the slightest bit looks encouraging inside the feeling that the cultivating network inside the examination space can greet energetically IPM methods for harvest security. From now of read, speculation of open assets in giving information concerning various methods for tormenter the board is amazingly viable. The urgent job of augmentation administrations, prominently on issues related with yield insurance, should be unquestionably fortified. Clearly, there's decent space for ranchers to help their data on tormenter the board issues which can transform them to utilize pesticides to a lesser degree, anyway extra adequately. Giving new thoughts on yield security, as IPM, to ranchers is significant, anyway insufficient. instructing and augmentation administrations related with the new thoughts likewise are fundamental. data will fabricate ranchers become extra aware of compound dangers and later on cause changes in offensive demeanors and hazardous practices [2].

Ryang et al. abridge the common sense of ensuring pieces of clothing, Gore-Tex had a great reasonableness as far as pesticide-verification, water-oil repellency, water transmission, strength, while water-oil repellent completed Sontara was keen as far as pesticide-confirmation, low buildup, brilliant air penetrability and vapor transmission. It is previously mentioned that these outcomes were brought about by the different geometric structures that caused the varieties in pore conveyance, material sythesis quantitative connection, physical-synthetic properties, completing operators and methodologies. The reasonableness of securing piece of attire material is foreseen to impact solace of articles of clothing [3].

Lagsana et al. created 3 primary mediation instruments; imaginative concoction packs, individual test move innovation and little ranch land synthetic training were encased inside the inventive compound unit model for homestead wellbeing police examination program and designed for assessing the investigation adequacy by correlation relationship of substance deposits in kale turn out previously and when the intercession. Study group results, show wilted proteolytic compound restraint at post mediation sum, contrasted and pre-intercession of fifty one.9\% at p-esteem < zero.011, uncover that the mediation program affect decrease of substance hindrance at zero. $05 \%$ significance level [4].

\section{Published By:}

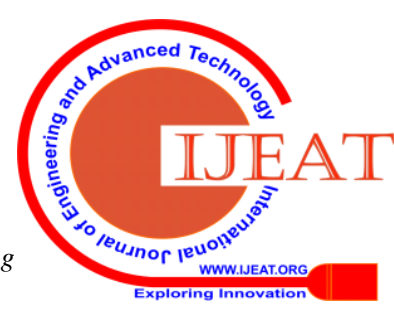




\section{Safety Pesticides Indicator using Hardware Model}

Rohallah et al. built up a preventive intercessions for diminishing movement dangers and medical problems among ranchers need the ID of things causative to perilous conduct, anyway investigation regarding this matter is confined. A hypothetical model for learning components moving ranchers' utilization of action security and wellbeing (OSH) rehearses in Persia was created. The model was through exact perception tried exploitation data gathered from a study of 301 tomato ranchers of Zanjan Province of Persia. The inspected OSH practices enveloped a huge shift of practices, arranged in four classes, i.e., utilization of pesticides, utilization of apparatus, utilization of private securing instrumentation, and applying designing standards (i.e., fitting the assignment to the individual, thinking of the work bolstered human variables, mulling over the connection between the working environment and the laborers, effort at task) [5].

Pesticide focuses were resolved chiefly in August, in concurrence with the concoction application sum by Elsa et al. Among the six prospected pesticides, azoxystrobin presented the absolute best recognition recurrence, proposing its wide use inside the Lower Mondego. Outstandingly, unlawful weed executioner gave the second most noteworthy recurrence, in this way light the need for legacy synthetics to be encased in recognition programs in order to supply sensible pesticide evaluation [6].

Rother et al. examined 5 factors zone unit offered that substance end-clients ought to achieve in the meantime in order to know and analyze the information found on a compound name. it's contended that end-clients in Low and Middle-Income Countries (LMIC) territory unit unfit to satisfy these elements for social, social, political, and financial reasons. These components are: access to the name, appropriate language, sufficient achievement level (for perusing and understanding) and access to instrumentation and offices. With mark information being a poor hazard correspondence vehicle, it's contended that the use of the expression "abuse" of pesticides inside the writing, by controllers and business unacceptably allocates fault of poisonings and natural tainting to complete clients [7].

Mohammed et al. depicts the Understanding current data levels and private convictions of ranchers might be a beginning for partner right comprehension of wellbeing practices. Discoveries of this examination found thatwillingness to utilize PPE among smallscale farmerswhenworkingwith pesticides is intently related to their impression of PPE quality. Accordingly, it's important to comprehend, comprehend, and mull over ranchers' inclinations in augmentation projects intended to advertise wellbeing measures all through working with pesticides. Clearly, expanding ranchers' view of the significance of PPE and expanding ranchers' aura to pursue should be a need altogether little scale ranchers in future preparing programs. This is frequently a huge objective for wellbeing specialists to consider once they have styled and procured proper instructive materials [8].

Winter et al. broke down the suitable dimensions for synthetic buildups in sustenances, alluded to as resistances inside the North American country and as most buildup limits (MRLs) in a great deal of the planet, square measure wide anyway unacceptably saw as dimensions of wellbeing concern. a one of a kind way to deal with grow deductively defendable dimensions of wellbeing concern is given related a guide to work out intense and interminable compound sanitation typical (PFSS) levels for the antimycotic captan on strawberries is given. exploitation this methodology, the unending PFSS level for captan on strawberries made up our psyches to be two $000 \mathrm{mg} \mathrm{kg}-1$ and furthermore the intense PFSS level made up our brains to be $250 \mathrm{mg} \mathrm{kg}-1$ [9]

Zhang et al. audited the positive edges of agrarian synthetic use yet as some potential negative effects on the setting and sanitation. moreover, abuse the instance of American state, we tend to examine the need for every buildup perception and successful tormenter the executives to showcase sanitation. Twenty years' concoction buildup information from California's synthetic buildup program were investigated. Results demonstrated that very ninety fifth of sustenance tests were in consistence with United States concoction buildup norms (resiliences). In any case, bound products from bound sources had high rates of deposits over resilience levels. Indeed, even once buildups over resistance levels were distinguished, most were at levels well underneath one $\mathrm{mg}$ $\mathrm{kg}-1$, and most presented irrelevant intense wellbeing hazard. Be that as it may, many identified buildups could cause wellbeing impacts. In this manner, building up a decent sustenance buildup program is imperative to affirm nourishment quality all through the commercial center [10]

\section{PROPOSED METHOD}

To identify the volume and calculating volume of the pesticides still now the farmer is a station which is termed as safety pesticide indicator .In the volume of the indicator. We will calculate according to its toxic content and the type of pesticides. It will predict the toxic of the pesticide and give the concerned amount of pesticide. This would be shown to the farmers whom check the volume of the pesticide and toxic of pesticides. Hence most of the harmful pesticides are used by farmers by officially with some fake information or permission about the pesticides as if the plants,soil and humans get affected.This is the existing system till now"we have protect our agricultural field from damaged by these harmful pesticides.In some countries indicators are used for the farmers wealth and humans health".

This project is designed as to stop affecting of plants, soil and humans from harmful pesticides.hence the idea is to implemented the safety pesticide indicator.As each and every farmer will stop the spraying of harmful pesticides without limitations i.e., borox, boric acid,chlordane,dinocap...etc.,. These are the active ingredents pesticides, with help of safety pesticide indicator we can able to control the overflow of pesticides.We set the concerned limit of pesticide for the concerned speicies. Thus we can protect our agricultural field and humans health. Figure 2 shows the block diagram and working principle of our proposed method. Figure 3 shows the hardware model for the proposed method.

Published By: 


\section{CONCLUSION}

Safety pesticide indicator is a useful tool to contribute towards more compliance with farmers. It could reduce the hazardous of pesticides that attack the plants, soil and human health and also useful for the person who are not to know how many amount of pesticide is used to plants. A reduction in overflow of pesticides. There are still some issues and challenges for this technology and hardware which require more research and development work.New application of these systems are expected, both for farmers and agricultural field.

\section{REFERENCES}

1. Bhandari, G., Atreya, K., Yang, X., Fan, L., \& Geissen, V. (2018). Factors affecting pesticide safety behaviour: The perceptions of Nepalese farmers and retailers. Science of The Total Environment, 631, 1560-1571.

2. Khan, M., \& Damalas, C. A. (2015). Farmers' knowledge about common pests and pesticide safety in conventional cotton production in Pakistan. Crop Protection, 77, 45-51.

3. Kim, R. H., Kwon, Y. G., Lee, H. Y., \& Lim, J. Y. (2015). Safety Evaluation of Pesticide-Proof Materials for Agricultural Clothing Using in-Vivo Test. Procedia Manufacturing, 3, 1888-1895.

4. Leuprasert, L., Monmora, S., Puydecha, M., Chapman, R. S., Siriwong, W., \& Taneepanichskul, S. (2014). Innovative Pesticide Kit Model for Vegetable Farm Safety Surveillance Program. APCBEE procedia, 10, 170-176.

5. Rezaei, R., Damalas, C. A., \& Abdollahzadeh, G. (2018). Understanding farmers' safety behaviour towards pesticide exposure and other occupational risks: The case of Zanjan, Iran. Science of The Total Environment, 616, 1190-1198.

6. Rodrigues, E. T., Alpendurada, M. F., Ramos, F., \& Pardal, M. Â. (2018). Environmental and human health risk indicators for agricultural pesticides in estuaries. Ecotoxicology and environmental safety, 150, 224-231.

7. Rother, H. A. (2018). Pesticide Labels: Protecting Liability or Health?-Unpacking "misuse" of pesticides. Current Opinion in Environmental Science \& Health.

8. Sharifzadeh, M. S., Damalas, C. A., \& Abdollahzadeh, G. (2017). Perceived usefulness of personal protective equipment in pesticide use predicts farmers' willingness to use it. Science of The Total Environment, 609, 517-523.

9. Winter, C. K., \& Jara, E. A. (2015). Pesticide food safety standards as companions to tolerances and maximum residue limits. Journal of Integrative Agriculture, 14(11), 2358-2364.

10. Zhang, M., Zeiss, M. R., \& Geng, S. (2015). Agricultural pesticide use and food safety: California's model. Journal of Integrative Agriculture, 14(11), 2340-2357.

11. http://sf.jki.bund.de/oecd-prier/secured/index.jsf.

12. http://www.pesticidemodel.eu/hair/home

13. http://www.pesticidemodels.eu/hair/hair2010

14. http://www.pesticidemodels.eu/hair/hair2014

\section{AUTHORS PROFILE}

Dr. S.Karkuzhali received the B.E degree in Computer Science and Engineering from the Arulmigu Kalasalingam College of Engineering affiliated to Anna University, Chennai in 2008, and the M.E. degree in Computer and Communication Engineering from the National Engineering College affiliated to Anna University of Technology Tirunelveli, in 2011. She secured first rank in her
M.E degree under those colleges which are affiliated under Anna University of Technology Tirunelveli. She completed her PhD (Information and Communication Engineering) and the thesis entitled "Analysis of retinal images for diagnosis of Eye Diseases using Feature Extraction" in Anna University, Chennai. She is currently working as Associate Professor in Kalasalingam Academy of Research and Education. Her research interests are in the areas of Medical image processing, Computer vision, Pattern Recognition, and Soft Computing techniques. She had published more than thirty papers in National, International Journals and Conferences 


\section{Safety Pesticides Indicator using Hardware Model}

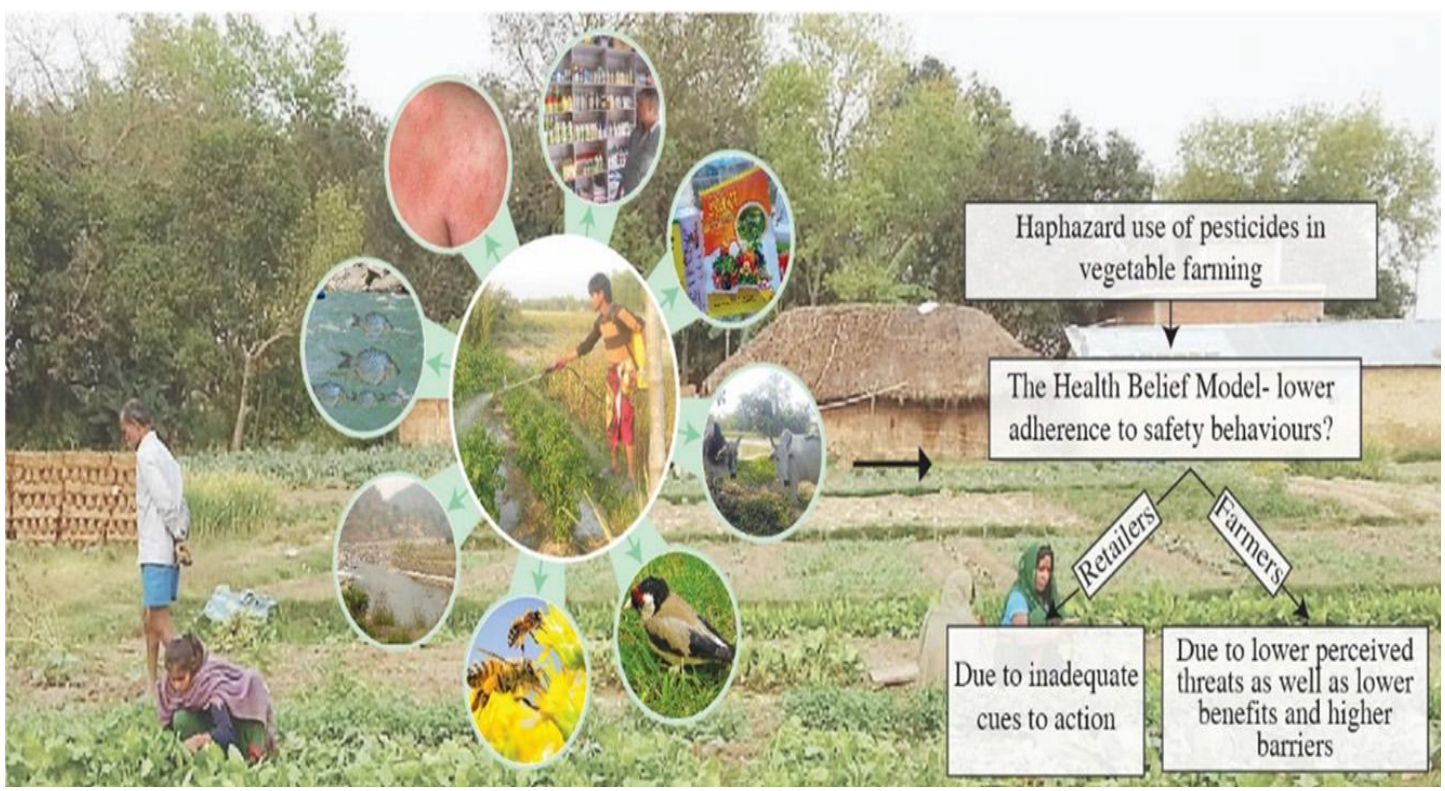

Figure 1: Need for Safety pesticide indicator

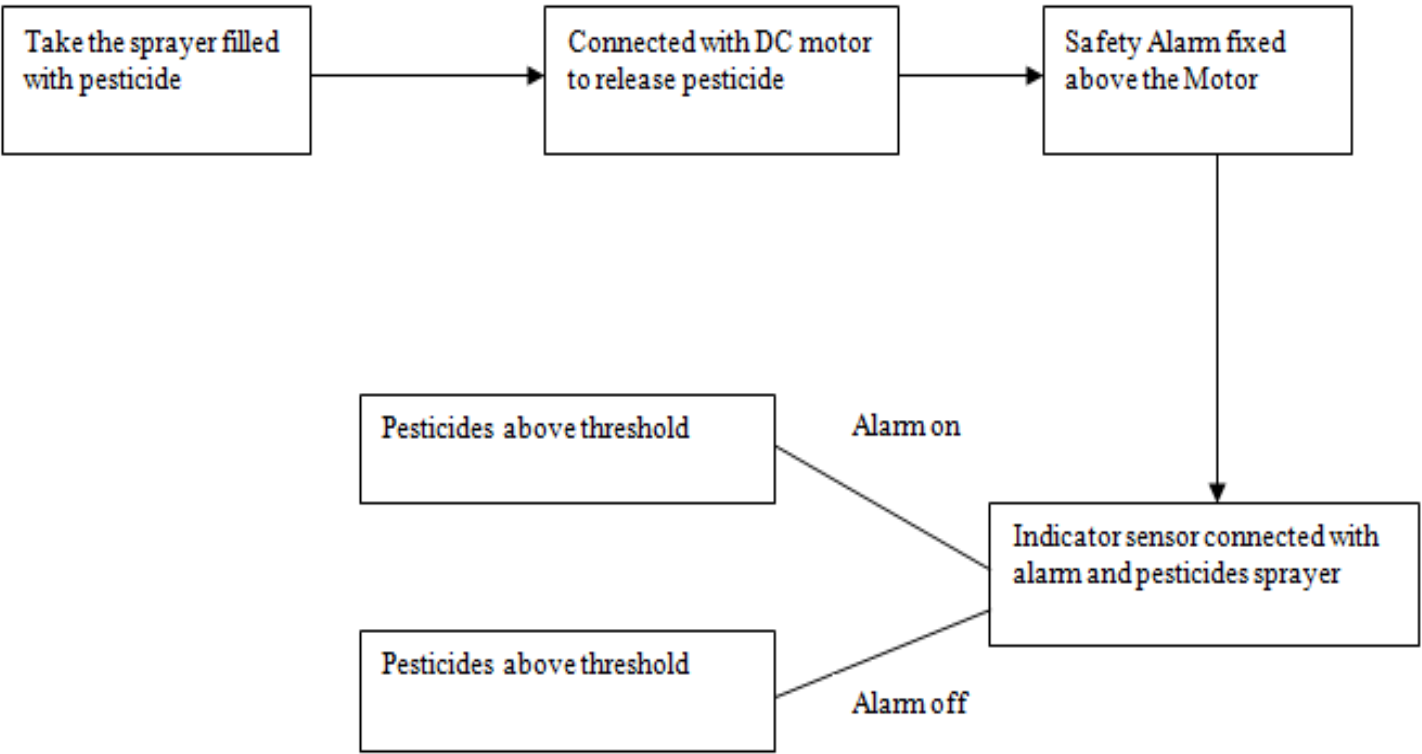

Figure 2: Block diagram for safety pesticides indicator using Sensor device

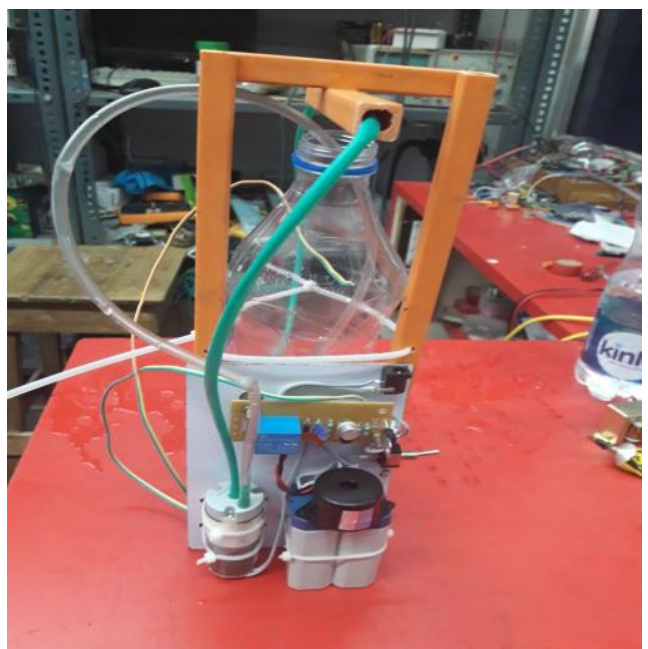

Figure 3:Hardware Model of Safety pesticide indicator 